\title{
Diacronie
}

Studi di Storia Contemporanea

$\mathrm{N}^{\circ} 31,3$ | 2017

"Le armi della politica, la politica delle armi"

\section{Proyecciones de memoria del largo 1917}

Ecos simbólicos en el Partido Comunista de España y el Partido

Comunista Italiano

\section{Andrea Donofrio y José Carlos Rueda Laffond}

\section{(2) OpenEdition}

Journals

\section{Edición electrónica}

URL: http://journals.openedition.org/diacronie/6107

DOI: 10.4000/diacronie.6107

ISSN: 2038-0925

\section{Editor}

Association culturelle Diacronie

Referencia electrónica

Andrea Donofrio y José Carlos Rueda Laffond, «Proyecciones de memoria del largo 1917 », Diacronie [En línea], №31, 3 | 2017, documento 2, Puesto en línea el 29 octubre 2017, consultado el 19 abril 2019. URL : http://journals.openedition.org/diacronie/6107 ; DOI : 10.4000/diacronie.6107 


\title{
Diacronie
}

Studi di Storia Contemporanea

$31,3 / 2017$

"Le armi della politica, la politica delle armi". Ideologie di lotta ed esperienze di guerra

\section{Proyecciones de memoria del largo 1917: ecos simbólicos en el Partido Comunista de España y el Partido Comunista Italiano}

\author{
Andrea DONOFRIO \\ José Carlos RUEDA LAFFOND
}

Per citare questo articolo:

DONOFRIO, Andrea, RUEDA LAFFOND, José Carlos «Proyecciones de memoria del largo 1917: ecos simbólicos en el Partido Comunista de España y el Partido Comunista Italiano», Diacronie. Studi di Storia Contemporanea : "Le armi della politica, la politica delle armi". Ideologie di lotta ed esperienze di guerra, 31, 3/2017, 29/10/2017,

URL: < http://www.studistorici.com/2017/10/29/donofrio-rueda_numero_31/ >

Diacronie Studi di Storia Contemporanea $\rightarrow$ http://www.diacronie.it Rivista storica online. Uscita trimestrale.

redazione.diacronie@hotmail.it

Comitato di direzione: Naor Ben-Yehoyada - João Fábio Bertonha - Christopher Denis-Delacour - Maximiliano Fuentes Codera Anders Granås Kjøstvedt - John Paul Newman - Deborah Paci - Niccolò Pianciola - Spyridon Ploumidis - Wilko Graf Von Hardenberg

Comitato di redazione: Jacopo Bassi - Luca Bufarale - Gianluca Canè - Fausto Pietrancosta - Alessandro Salvador - Matteo Tomasoni Diritti: gli articoli di Diacronie. Studi di Storia Contemporanea sono pubblicati sotto licenza Creative Commons 3.0. Possono essere riprodotti e modificati a patto di indicare eventuali modifiche dei contenuti, di riconoscere la paternità dell'opera e di condividerla allo stesso modo. La citazione di estratti è comunque sempre autorizzata, nei limiti previsti dalla legge. 


\title{
2/ Proyecciones de memoria del largo 1917: ecos simbólicos en el Partido Comunista de España y el Partido Comunista Italiano $^{1}$
}

\author{
Andrea DONOFRIO \\ José Carlos RUEDA LAFFOND
}

El artículo analiza varias modalidades de recuerdo sobre 1917 y la revolución soviética, centrándose en algunas estrategias de memoria del Partido Comunista de España (PCE) y el Partido Comunista italiano (PCI). Se atiende brevemente a cuatro coyunturas históricas diferenciadas (1937, 1949, 1956 y 1988), pero que permiten advertir los fenómenos de modulación, inflexión y actualización del recuerdo sobre el «largo 1917». Varios aspectos (capital simbólico, memoria cosmopolita o nacionalización) sirven, a su vez, de ejes donde inscribir las políticas de memoria comunista en ese dilatado devenir temporal..

Elenco delle abbreviazioni degli archivi citati

AGA $=$ Archivo General de la Administración

AHPCE $=$ Archivo Histórico del PCE

RGASPI = Arkhiv Sotsial'no-Politicheskoy Istorii

\section{Introducción}

Marco Albeltaro ha resaltado como rasgo histórico distintivo del comunismo su carácter de «ideología profundamente invasiva que ha plasmado la vida de sus militantes» ${ }^{2}$. Este hecho se manifestó a través de una cultura política codificada, pero también relativamente dúctil, plagada de prescripciones, ritos, liturgias o referentes simbólicos que se proyectaron con fuerza sobre el ámbito público y la esfera privada de sus seguidores. Aunque presentó modulaciones de sentido, el eco de 1917 como lugar de memoria y matriz primordial de la cultura comunista fue una

\footnotetext{
${ }^{1}$ Resultado del Proyecto «Diccionario de símbolos políticos y sociales: claves iconográficas, lugares de memoria e hitos simbólicos en el imaginario español del siglo XX» (Programa Estatal de Fomento de la Investigación Científica y Técnica de Excelencia, Mineco, ref. HAR2016-77416-P). Por cuestiones de espacio se han limitado las referencias bibliográficas y de archivo.

${ }^{2}$ ALBELTARO, Marco, Cultura política, estilos de vida y dimensión existencial. El caso de los comunistas italianos, in $\mathrm{BOSCH}$, Aurora, SAZ, Ismael (eds.), Izquierdas y derechas ante el espejo. Culturas políticas en conflicto, Valencia, Tirant le Blanch, 2015, pp. 363-378, p. 364.
} 
constante en las organizaciones nacionales. El discurso y la experiencia orgánica de los partidos de Europa Occidental siempre tuvieron presente, como capital simbólico, el ejemplo de la revolución bolchevique. Aquel acontecimiento estuvo dotado, al menos hasta la década de los sesenta, de una impronta heroica, erigiéndose en modelo que certificaba la posibilidad del cambio histórico y en certidumbre acerca de la virtualidad del tránsito al socialismo entendido como estadio superior.

Las celebraciones de la efeméride de Octubre de 1917, o de la figura de Lenin como su inspirador y artífice y arquitecto del Estado soviético, formaron parte del aparato conmemorativo de los partidos comunistas europeos. Lenin y la revolución se constituyeron en perdurables lugares de memoria con naturaleza inclusiva, orientándose a reforzar la identidad y los lazos del partido como comunidad mnemónica. Pero también excluyente, al ser unas marcas que evocaban el sentido anticapitalista del proyecto comunista, o al manejar el objetivo finalista de una emancipación socioeconómica vinculada, de una u otra forma, con la lucha de clases.

Otra característica de la cultura comunista fue la importancia otorgada a las estrategias proselitistas y socializadoras. El objetivo de erigirse en partidos de masas «de nuevo tipo», en oposición a la socialdemocracia, el anarcosindicalismo o a los considerados como partidos burgueses, figuró en el discurso público de los años treinta o cuarenta, en la Guerra Fría o durante la experiencia eurocomunista. Más allá de las evidentes singularidades de esos contextos, el recurso simbólico a los lugares de memoria se orientó a ampliar y reforzar la cohesión interna combinando dos marcos de encuadre en los discursos orgánicos: el nacional y el internacional. El eco de 1917, la retórica del internacionalismo proletario, el antifascismo o la solidaridad entre las organizaciones comunistas, así como las prácticas específicas derivadas de la vinculación al Komintern (IC, 1919-1943) o al Kominform (1947-1956), dieron forma tangible al sentido transterritorial del proyecto comunista ${ }^{3}$.

Paralelamente, los partidos comunistas actuaron como instrumentos nacionalizadores mediante narrativas generalistas y mecánicas institucionalizadas ${ }^{4}$. La movilización de referentes nacionales (o nacionalistas) fue muy visible en coyunturas como la Guerra Civil española, la II Guerra Mundial desde 1941 o coincidiendo con el episodio de colaboración vivido en Francia o Italia hasta mayo de 1947, cuando el PCI y su homólogo francés jugaron un papel esencial en la edificación del orden democrático de posguerra. De ese modo, a los mitos simbólicos derivados del paradigma de 1917, o al rol modélico otorgado al ejemplo soviético, se añadieron otras prácticas

\footnotetext{
${ }^{3}$ Cfr. STUDER, Brigitte, The Transnational World of the Cominternians, Houndmills, Palgrave, 2015, pp. 5-9; KIRSCHENBAUM, Lisa A., International Communism and the Spanish Civil War. Solidarity and Suspicion, Cambridge, Cambridge University Press, 2015.

${ }^{4}$ Sobre las prácticas de nacionalización sigue siendo fundamental MOSSE, George L., La nacionalización de las masas. Simbolismo político y movimientos de masas en Alemania desde las Guerras Napoleónicas al Tercer Reich, Madrid, Marcial Pons, 2005.
} 
como la interiorización de los colores nacionales, el constitucionalismo o el recurso a otros elementos simbólicos de gran espectro propios de la historia nacional y la tradición liberaldemocrática o radical (revoluciones de 1789 o 1848, jacobinismo, Comuna de París, unificación italiana, figuras de Garibaldi o Jaurès, etc.).

Se produjo así un acoplamiento entre valores emplazados en distintas escalas territoriales y simbólicas. Ahí se integraron esas huellas nacionales selectivas, así como la propia memoria sobre el carácter local asociado a cada partido comunista, en combinación con una memoria cosmopolita de mayor alcance donde figuró 1917 como cita compartida. La categoría de memoria cosmopolita alude a la producción y circulación transnacional de prácticas de recuerdo, a las formas de confluencia, y asimilación de referentes foráneos, o a fenómenos de hibridación e intersección «glocal, donde ciertos valores de corte global se adecuarían a parámetros específicos singulares (locales). Frente al sentido tópico y restrictivo habitualmente otorgado a la categoría de memoria nacional, la noción de memoria cosmopolita flexibilizaría, por tanto, las escalas geográficas y culturales donde se habría ubicado el recuerdo colectivo ${ }^{5}$.

Las siguientes páginas se aproximarán a cuatro momentos - 1937, 1949, 1956 y 1988 - donde tuvieron lugar otros tantos ejercicios de recreación de la revolución bolchevique: el vigésimo aniversario de Octubre, el septuagésimo aniversario de Iósif Stalin, el XX Congreso del Partido Comunista de la Unión Soviética (PCUS) y la polémica -protagonizada por Napolitano, Ingrao y Bufalini, entre otros- sobre la actitud de Palmiro Togliatti respecto al mito de la Revolución y la desestalinización. Esas cuatro situaciones permitirán advertir usos de memoria concretos en esa intersección entre lo internacional y lo nacional. Para recalcarla se adoptará una doble mirada sobre Italia y España que resalte los rasgos de especificidad y/o afinidad en relación con el relato internacional comunista.

\section{1937: exportación y españolización simbólica}

La celebración del vigésimo aniversario de la revolución bolchevique se produjo en un año crucial para la consolidación del régimen soviético. 1937 fue, como resaltó Schögel, el epicentro del terror y la utopía, el momento nuclear en la oleada de violencia sociopolítica nutrida por los Procesos de Moscú y las purgas en el interior del partido, pero también cuando se expresó con mayor claridad el sesgo del estalinismo como proyecto de modernización y cambio totalizador a gran escala ${ }^{6}$. Asimismo coincidió con la cristalización del «nacional bolchevismo», o «bolchevismo popular», una narrativa asequible que manejó una visión teleológica del progreso y un capital

\footnotetext{
${ }^{5}$ LEVY, David, SZNAIDER, Natan, «Memory unbound: The Holocaust and the formation of cosmopolitanism memory», in European Journal of Social Theory 5, 1/2002, pp. 87-106.

${ }^{6}$ SCHLÖGEL, Karl, Terror y utopía. Moscú en 1937, Barcelona, Acantilado, 2014.
} 
simbólico que incluía una concepción trascendental del socialismo, la exaltación del culto a la personalidad y del liderazgo histórico del partido, la obsesión por la formación de nuevos cuadros, la épica de la emulación y el sacrificio (el heroísmo estajanovista), el mito del «hombre nuevo» o el nacionalismo panruso ${ }^{7}$. En paralelo, las purgas políticas se acompañaron de expectativas y posibilidades de promoción y cooptación para nuevas generaciones de dirigentes o militantes.

El pabellón soviético en la Exposición Universal de París de 1937 sirvió de emplazamiento emblemático para proyectar ese tipo de valores fuera de las fronteras de la URSS. Al tiempo, la política soviética y la estrategia establecida desde la IC remarcaron la necesidad de la proyección internacional -la exportación- de un imaginario de memoria sobre la revolución bolchevique que se ajustase a los intereses diplomáticos y al discurso general sobre el antifascismo en su traducción comunista. Si bien diversos partidos se implicaron en la difusión de dichos valores ecaso del PCE o el PCF -, estos no fueron las herramientas exclusivas. Varias directivas dictadas por el Secretariado Ejecutivo de la IC destacaron en los meses anteriores a octubre de 1937 la relevancia y operatividad de otros colectivos definidos como organizaciones de masas formalmente autónomas, susceptibles de movilizar y encuadrar apoyos sociopolíticos e intelectuales de amplio espectro que superasen el campo estricto de las siglas y la afiliación comunista.

Ahí se situaron el Socorro Rojo Internacional (SRI), grupos de cooperación cultural o deportiva o el tejido de Asociaciones de Amigos de la Unión Soviética (AUS). Estas instituciones habían surgido en diferentes puntos de Europa o América Latina desde finales de los años veinte y fueron reactivadas en el otoño de 1936 como instrumentos proselitistas para difundir en los países capitalistas los logros de la «construcción del socialismo», la Constitución de 1936 o la «política de paz de la URSS». Durante 1937 canalizaron una ingente cantidad de materiales propagandísticos y fomentaron las visitas organizadas a la Unión Soviética ${ }^{8}$. Su operatoria, en conexión con otros organismos oficiales soviéticos, se articuló desde varios preceptos: orientarse hacia un vasto «público antifascista» integrado por trabajadores socialistas o anarquistas y clases medias reformistas, movilizar una «intensa actividad cotidiana» con «especial atención a las formas de trabajo que permitan una penetración en amplios sectores de la población» y, en definitiva, «crear una atmósfera en la que cualquier acción antisoviética sea simplemente imposible»"

Sin duda fue en la España en guerra donde la campaña de memoria por el vigésimo aniversario de 1917 alcanzó mayor grado de visibilidad, al hilo de la denominada «Semana de Homenaje a la URSS» organizada por la AUS durante los primeros días de noviembre de 1937. Aquella

\footnotetext{
${ }^{7}$ PRIESTLAND, David, Bandera roja. Historia política y cultural del comunismo, Barcelona, Crítica, 2010, pp. 167 et seq.

${ }^{8}$ Directiva de 11 de julio de 1937, Arkhiv Sotsial'no-Politicheskoy Istorii (desde ahora RGASPI), 495/18/1203.

${ }^{9}$ Directiva de septiembre de 1936, RGASPI, 495/18/1114.
} 
celebración fue un ejercicio de españolización -o indigenización- de 1917 como lugar de memoria donde se combinaron las marcas simbólicas soviéticas junto a la iconografía frentepopulista española mediante una profusión de iniciativas proselitistas nutridas de asambleas y conferencias, confección de periódicos murales, representaciones teatrales o proyecciones cinematográficas. Tampoco debe obviarse el momento de celebración de aquella efeméride en clave interna: 1937 representa, probablemente, el cénit en la capacidad de influencia política del PCE en la España republicana, y pocos meses antes de la conmemoración se produjeron los dramáticos acontecimientos del mayo barcelonés.

El PCE impulsó la reorganización de las secciones provinciales de la AUS con cierta anticipación. La madrileña se recompuso desde marzo de 1937 sumando representantes de diversas organizaciones políticas y sindicales. En todo caso, la hegemonía comunista resultó abrumadora. En junio algo más de 11.000 socios eran miembros del PCE y otros 3.000 de las Juventudes Socialistas Unificadas (JSU), frente a un millar escaso de afiliados socialistas, otros tantos anarco-sindicalistas o cerca de setecientos republicanos ${ }^{10}$. De ese modo quedó articulada la infraestructura humana para la conmemoración de 1917, una iniciativa potenciada y alimentada desde la URSS, gestionada en sus trazas esenciales por la IC, resuelta desde el PCE y encuadrada mediante la AUS, que dedicó en su organigrama y operatoria un visible espacio al componente no comunista.

La memoria de la revolución bolchevique en la España de 1937 se centró en recalcar su carácter popular, su orientación emancipadora y su sentido histórico como frontispicio de nueva era. De ahí los acusados paralelismos trazados entre las guerras civiles rusa y española entendidas como epopeyas libertadoras.

Madrid fue uno de los espacios que recogió esta iconografía híbrida. En ocasiones a través de grandes paneles callejeros, o bien mediante muestras de modesta arquitectura efímera, se reiteraron por toda la ciudad pautas de equivalencia simbólica: el hermanamiento entre las banderas nacionales, la correspondencia de liderazgo entre los partidos comunistas soviético y español, el homenaje a través de la monumentalización de los dirigentes soviéticos (retratos en los vanos de la Puerta de Alcalá), o la reconversión de piezas religiosas en laicas como ocurrió en el templete del puente de San Isidro, re-significado con banderines republicanos y emblemas de la AUS $^{11}$. A estas escenografías se añadió la exposición en los antiguos locales del Palacio de Hielo dedicada a la construcción socialista en la URSS con una selección de regalos que se enviarían a la Unión Soviética $^{12}$. Con tal motivo se reunió un amplio catálogo de artefactos que incluyeron la

\footnotetext{
${ }^{10}$ Informe de la Secretaría de Masas del Comité Provincial de Madrid, 1937, Archivo Histórico del PCE, Documentos, 18.

${ }^{11}$ Archivo General de la Administración, (AGA/C), 33F, 04070, 56180-001, 56184-001, 56183-001 y $56182-001$.

${ }^{12} \mathrm{AGA} / \mathrm{C}, 33 \mathrm{~F}, 04069,56127-001,56143-001,56144-001,56145-001,56185-001$ y 56186-001.
} 
primera bandera de las Brigadas Internacionales, pertrechos militares, un jersey de punto para Stalin o un traje de luces de Pepe Bienvenida ${ }^{13}$.

«La Semana de Homenaje a la URSS» debe enmarcarse, además, en la estrategia del PCE volcada en cualificar la Guerra Civil como lucha por la independencia nacional y al fascismo como agresión extranjera ${ }^{14}$. Desde el verano de 1936 se puso a punto una intensa maquinaria propagandística de corte nacionalista y patriótico que echó mano de referentes de memoria procedentes de la tradición liberal (el 2 de Mayo de 1808, la Guerra de la Independencia, las Cortes de Cádiz, los héroes progresistas decimonónicos, los padres del socialismo español...) ${ }^{15}$.

Este universo supra-comunista incluso formó parte de los materiales formativos preparados para la educación política de los voluntarios de las Brigadas Internacionales, si bien no era un empeño radicalmente nuevo. Un proyecto de expansión editorial estudiado por los servicios de la IC (Rdeizdat) a finales de 1935 resaltó ya la necesidad de lograr «una vasta y concreta penetración ideológica entre las grandes masas» españolas a través de la «nacionalización» de la oferta cultural mediante productos de amplio espectro, con obras históricas o clásicos literarios. Para ello se sugirió poner en marcha una colección («Nuestras Tierras») que incluyese un amplio corpus de biografías dedicadas a personajes tan variopintos como El Cid, Bolívar, los constituyentes de Cádiz, Mariana Pineda, Abd-el-Krim, Pancho Villa o Pablo Iglesias. Su comité editorial estaría compuesto por figuras de relieve literario como Valle Inclán, Eduardo Ortega y Gasset o García Lorca, aunque la responsabilidad del proyecto debía recaer en intelectuales del PCE como César e Irene Falcón, Pedro Garfias, Wenceslao Roces, César Arconada, Luis Lacasa o Ramón J. Sender. Con esta idea se antecedió la eficaz fórmula de expansión editorial materializada en la colección de libros populares «Nuestro Pueblo» que vio la luz tras julio de $1936^{16}$.

\section{1949: sovietización y apoteosis del culto a la personalidad}

El septuagésimo cumpleaños de Stalin, en diciembre de 1949, constituyó la primera gran liturgia del movimiento comunista internacional de la Guerra Fría. Estuvo dominada por una intensa proyección simbólica en clave de sovietización, en correspondencia con un ejercicio de afirmación de autoridad y poder de la URSS en Europa Central y Oriental. Su narrativa no se inscribió, como ocurrió en la España de 1937, en el discurso de cooperación frentepopulista, sino que pretendió reafirmar la sujeción de los partidos comunistas al epicentro encarnado en el PCUS.

\footnotetext{
${ }^{13}$ Mundo Obrero, 9 de octubre de 1937, p. 2.

${ }^{14}$ NÚÑEZ SEIXAS, Xosé M., ¡Fuera el invasor! Nacionalismos y movilización bélica durante la guerra civil española (1936-1939), Madrid, Marcial Pons, 2006.

${ }^{15}$ Historia del movimiento liberal y revolucionario de España hasta el 18 de Julio, manuscrito mecanografiado, [1938?]; RGASPI, 545/2/84.

${ }^{16}$ RGASPI, 495/78/138.
} 
Pero que se amplificasen pautas soviéticas muy definidas no entró en contradicción con la diversificación local que presentó su campaña de memoria, basada en personificar la figura de Stalin con el legado de 1917.

Los fastos de 1949 constituyeron la última gran exaltación del comunismo global concitada en torno a Stalin, presentado como expresión sublime de Lenin y de la huella idealizada de 1917; o como artífice de lo que Jean Marie Goulemot llamó la «sensibilidad estalinista» expresada a través de las ideas de superioridad, modernidad y solidaridad socialistas y mediante la imagen de «hombre de la paz» ${ }^{17}$. Según ha resaltado Alexey Tikhomirov respecto a la campaña de la onomástica en la República Democrática Alemana, esta pivotó sobre un elemento central -la sovieticidad- entendida como manto unificador que enfatizaba el rol de la URSS como paradigma para el movimiento comunista. Pero tal afirmación se combinó con el recurso a particularidades históricas, lingüísticas o folklóricas, o bien incorporando ejercicios de culto a los dirigentes locales. De ese modo se concitó un imaginario internacional unitario que hibridó el tono compartido del mito soviético junto a las «polifonías nacionales» ${ }^{18}$.

El homenaje a Stalin se reprodujo con intensidad en las nacientes democracias populares y en las organizaciones comunistas europeas occidentales. Constituyó un ejercicio de notable movilización simbólica que debe contextualizarse en los parámetros iniciales de la Guerra Fría, en el discurso de solidificación del bloque oriental y en la proyección global del modelo soviético en clave de idealizada respuesta anti-imperialista frente a Estados Unidos. Pero también se ajustó a los referentes patrióticos y a la memoria inmediata sobre la Resistencia antifascista según las particularidades locales. El PCI, por ejemplo, editó carteles que italianizaron al dirigente soviético, combinando su rostro con una secuencia combinada de banderas que alternaban la enseña roja y los colores nacionales. Otro cartel saludó el aniversario categorizando a Stalin como entregado a la causa del socialismo y la paz. El número especial publicado por L'Unità el 21 de diciembre de 1949 incluyó una biografía que remarcaba la lucha contra el fascismo italiano y la victoria en la II Guerra Mundial ${ }^{19}$. En las páginas de Rinascita, Palmiro Togliatti publicó un artículo extremadamente halagador de Stalin donde recalcó su rol de autoridad efectiva y simbólica, en coherencia con la semántica ortodoxa del culto a la personalidad.

Nos ha enseñado a ser comunistas, a luchar en cualquier condición, a ser fieles hasta el final a los principios del marxismo-leninismo, a servir a la causa de la emancipación de los

\footnotetext{
${ }^{17}$ GOULEMOT, Jean Marie, Pour l'amour de Staline. La face oubliée du communisme français, Paris, CNRS, 2009, p. 27.

${ }^{18}$ TIKHOMIROV, Alexey, The Stalin Cult Between Centre and Periphery. Structures of the Cult Community in the Empire of Socialism, 1949-1956-The Case of GDR, in ENNKER, Benno, HEIN-KIRCHER, Heidi (herausgegeben von), Der Führer im Europa des 20. Jahrhunderts, Marburg, Herder-Institut, 2010, pp. 297-321.

${ }^{19}$ L'Unità, 21 de diciembre de 1949, p. 4.
} 
trabajadores. Nos empeñamos en ser fieles a vuestras enseñanzas [...]. Os deseamos largos años de vida y de salud para el bien del pueblo de la Unión Soviética, para el bien de la clase obrera y de los pueblos del mundo entero. Gloria a usted, compañero Stalin! $!^{20}$.

No obstante, la figura de Stalin fue objeto de intensa pugna simbólica en la Italia de aquellos meses: ante los decisivos comicios de febrero de 1948, la Democracia Cristiana realizó una agresiva campaña de imagen que insistió en un anticomunismo atroz, con un imaginario simbólico que aludió a la barbarie roja, al orco bolchevique y al expansionismo soviético.

En el caso del PCE el homenaje se imbricó en una secuencia de intensa inflación simbólica donde figuró la conmemoración anual de la Revolución de Octubre (octubre-noviembre de 1949), la onomástica de Dolores Ibárruri (9 de diciembre) y el trigésimo aniversario del partido (abril de 1950). Estos episodios se explicaron a través de líneas de interconexión y retroalimentación fundadas en una codificación muy cerrada basada en la exaltación idealizada de 1917 y del liderazgo soviético, un agresivo discurso frente a la tradición socialdemócrata y liberalparlamentaria, el paralelismo en forma de culto reflejo entre Stalin y Pasionaria, el antifranquismo y la profunda revisión del recuerdo del antifascismo de los años treinta y cuarenta, ahora trastocado en anti-americanismo.

Inserto en estas coordenadas de sentido «Mundo Obrero» publicó un especial el 21 de diciembre encabezado por un texto de Pasionaria que reiteraba la cualificación de Stalin como "guía y esperanza de los pueblos»". El PCE, al igual que el resto de formaciones comunistas internacionales, animó una intensa campaña de envío de regalos a Moscú, en una suerte de contraprestación simbólica y homenaje según los códigos del culto a la personalidad. Los presentes, ofrendados desde el exilio o el interior -en ocasiones desde las cárceles franquistas-, incluyeron exvotos y reliquias laicas: viejos carnets, banderas de agrupaciones guerrilleras, escarapelas con los números de registro procedentes de las ropas usadas en campos de concentración nazis o un pisapapeles que recordaba un acto de sabotaje contra los alemanes en Francia $^{22}$.

El homenaje internacional a Stalin de 1949 constituyó, pues, un nuevo ejercicio de síntesis entre memoria cosmopolita e ingredientes de afectividad local, tal y como ocurrió en 1937. La retórica compartida incluyó lemas intercambiables entre las democracias populares y los comunistas occidentales. El más representativo subrayó la tesis de «Stalin es el mejor amigo de...». En esos puntos suspensivos cupieron por igual checoslovacos, alemanes, polacos, búlgaros, italianos o españoles del interior y del exilio, cohesionados simbólicamente mediante una

\footnotetext{
${ }^{20}$ Rinascita, 21 de diciembre de 1949, p. 1.

${ }^{21}$ Mundo Obrero, 21 de diciembre de 1949, p. 1.

${ }^{22}$ Mundo Obrero, 29 de diciembre de 1949, pp. 1-2.
} 
narrativa hagiográfica sobre la URSS y el liderazgo providencial de Stalin, el carisma sistémico del «largo 1917», o un lenguaje ritual y rutinario intercambiable por encima de las singularidades nacionales, pero asimismo adaptado a estas.

\section{1956: el shock del Informe Secreto y el giustificazionismo}

El XX Congreso del PCUS y la publicación del Informe Secreto tuvieron importantes repercusiones en los partidos comunistas. Como confesó Togliatti «una tempestad se ha abatido sobre nosotros» ${ }^{23}$. Era el «inicio oficial de la demolición del mito de Stalin $»^{24}$. Y si el año 1949 había significado la apoteosis del culto a la personalidad, 1956 fue el de su denuncia desde una lógica de exorcismo de memoria. En este contexto los principales partidos comunistas de Europa Occidental apostaron, en general, por una doble estrategia. Por un lado, personalizaron las acusaciones en la figura de Stalin, si bien destacando igualmente sus méritos en la construcción del socialismo en la URSS y su contribución al triunfo de la revolución. Y, por otro lado, para minimizar las posibles repercusiones, se prefirió sustituir la agresiva semántica que hablase de «crímenes» por «errores». De este modo el lenguaje jugó un importante rol funcional simbólico.

Pero la poderosa carga alegórica asociada a Stalin dificultó igualmente la asimilación de las críticas. Los partidos comunistas italiano o español buscaron un difícil equilibrio, un justo medio, entre el mito de la Revolución y la condena de quien había figurado antaño como su máximo exponente en tiempo presente. Se temía provocar un trauma en los militantes comunistas. Se terminó por culpar de las limitaciones de esta etapa al culto a la personalidad, apartando progresivamente su intensa sombra del escenario político, como un viejo cuadro que no se podía tirar y que había que guardar en el desván.

El PCI y el PCE se movieron, pues, entre la cautela y la reticencia de los dirigentes y la confusión y el ocasional estupor de la militancia. A la altura de 1956, Stalin era el fantasma que recorría los encuentros y foros internos. Se obvió su figura, se suavizó su dilatada etapa de poder y se intentó alternar el elogio y la crítica, un logro con un error. Desapareció de los editoriales de los periódicos comunistas, aunque siguió perviviendo ocasionalmente en las cartas a los directores o en los mítines de periferia.

Para el PCI 1956 representó una fecha crucial. Por su trascendencia se habló del «indimenticabile 1956». Fue un momento de gran dificultad que, desde un punto de vista estratégico, abrió paso definitivo a la redefinición de la «vía italiana al socialismo». Respecto al periodo estalinista, el partido consideraba necesarias las críticas, al mismo tiempo que enfatizó

\footnotetext{
${ }^{23}$ ERICE, Francisco, «Presentación», in Nuestra Historia, 2/2016, pp. 7-10, p. 7.

${ }^{24}$ FROIO, Felice, Togliatti e il dopo Stalin, Milano, Mursia, 1988, p. 2.
} 
aspectos como el difícil contexto en el que había actuado el líder georgiano. El partido decidió, en este escenario, prorratear el relato en el tiempo. La estrategia fue la de dosificar las noticias para limitar el impacto. En lugar de hacer público el Informe Secreto cuando empezó a difundirse en la URSS, el PCI fue desmembrando y descubriendo la cuestión en diferentes días y declaraciones, hablando de errores locales, infravaloración de graves problemas y buena $\mathrm{fe}^{25}$. En un primer momento, se intentó defender la idea de que los errores y los delitos cometidos por Stalin, por muy graves que fueran, respondían a «razones históricas». Incluso se argumentó su necesidad. Se empezó a hablar de giustificazionismo, produciéndose una clara división en el seno del partido entre aquellos que intentaron justificar la acción de Stalin y otros críticos más severos.

En una reunión del Consejo Nacional del PCI celebrada en marzo de 1956, Togliatti concluyó su intervención de la siguiente manera: «Stalin es un hombre que ha conquistado un lugar en la Historia. Y este lugar lo tiene y lo tendrá siempre en las conciencias de los hombres que saben entender las cosas $»^{26}$. El auditorio aplaudió como si nada hubiera pasado en aquellos meses. En su intervención Togliatti expresó un juicio positivo por su contribución a la experiencia bolchevique y respetó dos cuestiones: preservar la función mítica del georgiano, tan apreciada entre importantes sectores de la base o los cuadros orgánicos, y posponer el problema de la implicación del PCI en la política estaliniana ${ }^{27}$. En abril, de nuevo fue Togliatti quién afirmó que Stalin «se ha asegurado un lugar en la Historia al encabezar una obra ingente, la Revolución de Octubre, la construcción de la sociedad socialista, la afirmación y la defensa hasta el final de esta sociedad ${ }^{28}$. La insistencia en el contexto dramático fue una constante en el partido y una forma de justificar su relación con la URSS.

Tras estas posiciones iniciales, y el temor a la posible desorientación del colectivo comunista, la actitud del secretario general fue evolucionando entre una defensa de la línea general del PCUS y de su máximo dirigente - línea que, en sus palabras, fue correcta «antes de la guerra, en la guerra y después de la guerra» -, y la crítica de los defectos teóricos del líder y las «erróneas medidas de represión» ${ }^{29}$. La actitud del partido fue cautelosa, coherente con la visión de que pervivían los «trabajadores y militantes que tenían el retrato de Stalin en la pared, o en el corazón $»^{30}$.

\footnotetext{
${ }^{25}$ L'Unità nunca publicó el Informe y solo el 17 de junio admitió «la existencia de algunas formas de degeneración» en la URSS.

${ }^{26}$ PAJETTA, Gian Carlo, Le crisi che ho vissuto, Roma, Editori Riuniti, 1982, pp. 61-62.

${ }^{27}$ RIGHI, Maria Luisa, Quel terribile 1956, Roma, Editori Riuniti, 1996, p. XXXIV.

${ }^{28}$ HÖBEL, Alexander, «Renovación y continuidad. El Partido Comunista Italiano y el año 1956», in Nuestra Historia, 2/2016, pp. 11-30, p. 14.

${ }^{29}$ GUERRA, Adriano, Comunismo e comunisti, Bari, Dedalo, 2005, p. 210.

${ }^{30}$ La cautela se explica también por la proximidad de las elecciones administrativas (mayo 1956) y el miedo a que la «bomba» Jrushchov pudiera repercutir en el resultado. El entrecomillado en MAGRI, Lucio, Il sarto di Ulm, Milano, Il Saggiatore, 2009, p. 120.
} 
Solo tras la publicación del Informe Secreto en la prensa norteamericana y francesa, Togliatti decidió enfrentarse con el problema. Concedió una entrevista a «Nuovi Argomenti», titulada «Nueve preguntas sobre el estalinismo», centrada en el debate tras el cónclave soviético ${ }^{31}$. En ella criticó el exceso de poder personal en menoscabo de la gestión colegiada. Su línea argumental se movió en torno a dos ideas: reiterar los errores y, a la vez, considerar que estos no habían sido capaces de destruir los «elementos básicos de la sociedad soviética» ni su superioridad sobre «las modernas sociedades capitalistas». Y, en esta línea, merecía la pena recordar los valores de la revolución y su importancia, fijando su legado y balance estructural frente a la coyunturalidad del período estalinista.

Togliatti, al igual que otros dirigentes comunistas, consideró así que no se podía liquidar en una misma enmienda a la totalidad a Stalin y a la revolución. De este modo, la desacralización simbólica se acompañó de un reforzamiento de 1917 como capital simbólico y seña de identidad. Por tanto, tras el bache, se trataba sólo de emprender de nuevo el camino. El proceso había sufrido una desviación, pero no se había interrumpido ni se había visto definitivamente desvirtuado, y era esa pureza no mancillada la que permitía desplegar la vieja técnica de autocrítica colectiva, tan querida en la cultura comunista. «La demolición» de Stalin abrió «una profunda laceración en el corazón y en el cerebro de cada militante», pero fue el momento de reavivar la memoria de Octubre y la lucha antifascista ${ }^{32}$. Esta estrategia de memoria tendió a una neutralización selectiva del corto plazo en beneficio de la sombra idealizada de 1917 como matriz de presente y futuro. En coherencia con ello el debate del VIII Congreso utilizó frecuentemente la expresión "partido revolucionario» para remarcar la herencia de 1917 y facilitar el reacomodo identitario.

Aunque era evidente la dificultad dialéctica. Togliatti empleó a un mismo tiempo las expresiones «despotismo» y «gran marxista» para referirse a Stalin. Se trataba de acrobacias retóricas con el objetivo de evitar la «desorientación en nuestras filas», como confesó en su discurso ante el Consejo Nacional. Al tiempo, dejó entrever su disgusto ante el método utilizado por Jrushchov para reforzar su posición frente a la dirección soviética y desmarcarse del pasado. Lo consideró un exabrupto, una invectiva que abordaba temas traumáticos pero liquidándolos, sin establecer la necesaria claridad ideológica para profundizar en el camino a seguir.

Un suceso aparentemente anecdótico evidencia el arraigo del mito de Stalin entre algunos intelectuales. Entre mayo y agosto de 1956, Leonardo Sciascia escribió un breve texto irónico titulado La morte di Stalin que envió a Italo Calvino para conocer su opinión. Calvino afirmó en su respuesta que al leerlo se sintió incómodo. «Me resulta complicado», afirmó, «darte un juicio desapasionado. Hay demasiado de mi historia en ello». Sobre la ironía del relato consideró que

\footnotetext{
${ }^{31}$ Nuovi Argomenti, 20, 3/1956.

${ }^{32}$ MAGRI, Lucio, op. cit., p. 133.
} 
"cuando la realizan otros, no sé valorar objetivamente, me siento implicado»" ${ }^{33}$ Era evidente que el tono satírico le hiriós ${ }^{34}$. Aunque, a pesar del sentido irreverente del texto, Sciascia también se declaró «aún convencido de que Stalin ha sido un gran hombre, uno de los más grandes que la historia del mundo haya tenido», confesando sentir «una terrible confusión» ${ }^{35}$.

En el caso del PCE, una formación clandestina con un volumen de militantes muy inferior al del PCI y sometido a una notable dispersión geográfica, la desacralización de Stalin fue acogida con preocupación por sus posibles repercusiones internas y la probable campaña de reforzamiento anticomunista desde el régimen franquista. Siguiendo el mismo guión que el PCI, la narrativa oficial del PCE se apresuró a puntualizar que, pese a los errores, Stalin representó una figura histórica decisiva en el triunfo de la Revolución. Sus méritos en la construcción del socialismo no podían ser menospreciados.

Se trataba de contener el fuerte impacto psicológico de las revelaciones. Se temía que los militantes pudieran desanimarse o abandonar la lucha clandestina. No obstante, como afirmó Carrillo, «el conocimiento de las faltas de Stalin» provocó un hondo sentimiento, pero »en general, los camaradas aceptan las explicaciones dadas y comprenden» ${ }^{36}$. El PCE consiguió que el efecto emocional no se tradujese en daño político ni derivase en crisis orgánica. Al contrario, el discurso oficial interpretó la autocrítica como muestra de valentía: el movimiento comunista era capaz de replegarse, manifestar sus defectos, enmendarlos y regenerarse. Dentro de España se evidenciaron dos posturas diferenciadas: la de algunos «viejos camaradas» que rechazaron las acusaciones, y la vivida entre los colectivos más jóvenes donde el impacto personal fue más limitado y distante. Pero la respuesta unánime fue la lealtad al partido por encima de cualquier posible resquicio de fidelidad a Stalin.

En definitiva, 1956 representó «un momento de ruptura decisivo en la definición del universo simbólico comunista» ${ }^{37}$. En el PCI, superada la conmoción inicial del XX Congreso y los hechos de Hungría, Togliatti supo fortalecer su liderazgo. «No hay Estado ni partido-guía», afirmó, «la guía son nuestros principios, los intereses de la clase obrera y del pueblo italiano, la defensa permanente de la paz y de la independencia de la nación, los deberes de solidaridad

\footnotetext{
${ }^{33}$ Carta fechada 12 de septiembre de 1956, in CALVINO, Italo, Lettere 1945-1980, Milano, Mondadori, $2000, \mathrm{p}$. 463.

${ }^{34}$ En desacuerdo con la actitud del partido por los sucesos de Hungría, Calvino abandonó el PCI en 1957 y escribió un texto extremadamente crítico - e irónico - sobre el inmovilismo de Togliatti («La grande bonaccia delle Antille», in Città aperta, I, 4-5/1957).

${ }^{35}$ Carta del 16 de septiembre de 1956, citada in MANGONI, Luisa, Pensare i libri. La casa editrice Einaudi dagli anni trenta agli anni sessanta, Torino, Bollati Boringhieri, 1999, p. 860.

${ }^{36}$ ERICE, Francisco, «El Partido Comunista de España, el giro de 1956 y la lectura selectiva del XX Congreso», in Nuestra Historia, 2/2016, pp. 66-88, p. 71.

${ }^{37}$ YSÁS, Pere, MOLINERO, Carme, De la hegemonía a la autodestrucción, Barcelona, Crítica, 2017, p. 20.
} 
internacional $»^{38}$. El «terribile 1956» del PCI se selló con algunos cambios internos y con una mayor propensión al debate dentro de los límites marcados por el centralismo democrático ${ }^{39}$.

En 1957, en el cuadragésimo aniversario de Octubre, el PCI y el PCE subrayaron su proximidad a la URSS, halagaron el camino recorrido y defendieron la unidad del movimiento comunista internacional sobre la base del marxismo-leninismo. Con ocasión de la conmemoración algún periódico acompañó la noticia con la foto emblema de la censura estalinista: Lenin arengando sobre una tribuna de madera mientras Trotsky, en la escalera, miraba al pueblo. Esa instantánea no coincidió con ningún tipo de rehabilitación de Trotsky, pero sí con una postura de nacionalización identitaria y ruptura. Apareció coincidiendo con la afirmación de que debía celebrarse, «como ella solo se merecía», la Revolución de Octubre, aunque en la práctica ambas formaciones estaban ahondando un camino que les llevaría en pocos años a distanciarse de la URSS en aras de sustanciar la tesis de las vías propias al socialismo ${ }^{40}$.

\section{1988: revisionismo y juicio final}

Tras la muerte de Enrico Berlinguer en 1984 y el inicio de la Perestroika promovida por Mijaíl Gorbachov, el PCI empezó una nueva etapa. Si por un lado se puso de manifiesto que «el menos preparado por la muerte de Berlinguer es el mismo $\mathrm{PCI}{ }^{41}$, por otro se dio paso a una etapa de reflexión sobre la identidad del partido, marcada por una pérdida paulatina de militantes y votos.

El septuagésimo aniversario de la Revolución de Octubre ya no se vivió con los fastos y la emotividad de antaño. Se trataba de un lento declive. En 1968 tuvo lugar la sonada condena del PCI a la URSS por la intervención armada en la Primavera de Praga y, años después, Berlinguer afirmó amargamente que los hechos de Polonia inducían a considerar «el agotamiento de la fuerza propulsora de la Revolución de Octubre» ${ }^{42}$. En las celebraciones por el aniversario de 1987 en Moscú la delegación del PCI estuvo compuesta solo por el entonces secretario Alessandro Natta y por Giorgio Napolitano. Ambos indicaron que habían aceptado participar «en cuanto se trataba de un encuentro internacional al que fueron invitados los partidos socialistas y socialdemócratas, además de los movimientos progresistas y las formaciones políticas de diferentes naturaleza, por

\footnotetext{
${ }^{38}$ VACCA, Giovanni, Saggio su Togliatti e la tradizione comunista, Bari, De Dorato, 1974, p. 330.

${ }^{39}$ La alusión al terrible 1956, en el capítulo IV del libro de AMENDOLA, Giorgio, Il rinnovamento del PCI, Roma, Editori Riuniti, 1978, mientras que el capítulo V del ya citado libro de Claudio Magri tuvo por título «El shock del XX Congreso».

${ }^{40}$ El entrecomillado, palabras de Fernando Claudín reproducidas in JULIÁ, Santos, Camarada Javier Pradera, Barcelona, Galaxia Gutenberg, 2012, p. 62.

${ }^{41}$ La Vanguardia, 14 de junio de 1984, p.8.

42 MAMMARELLA, Giuseppe, Il partito comunista italiano, in PASQUINO, Gianfranco, La política italiana. Dizionario critico 1945-95, Roma-Bari, Laterza, 1995, pp. 287-310, p. 303.
} 
ejemplo el Partido del Congreso de la India» ${ }^{43}$. Era evidente que formar parte de la delegación ya no era un mérito o una distinción, sino casi una obligación institucional. Tanto en su discurso en la capital soviética como en el de Módena -donde se celebró una fiesta por el aniversario-, Natta tildó de «anacrónicos» y «no productivos» los «intentos de restablecer un movimiento comunista internacional cerrado en sí mismo y tendente a revivir una vieja ortodoxia doctrinaria» ${ }^{44}$.

En febrero de 1988, tras la rehabilitación de Nikolái Bujarin en la URSS, estalló en la prensa italiana el llamado "caso Togliatti». En él se reavivó la crítica acerca del comportamiento de il Migliore respecto a la violencia estalinista. El punto álgido del debate se alcanzó tras la publicación de un artículo de Umberto Cardia, el 24 de febrero en «L'Unità» titulado «Per Gramsci fu fatto tutto?». En él se cuestionaba si Togliatti y el PCI habían abandonado a Gramsci a su triste destino en la cárcel, entre otros aspectos, por sus críticas a Stalin. Se recordaba cómo Togliatti nunca entregó una carta escrita por Gramsci el 14 de octubre de 1926 en la que se aludía a que Stalin «no ganase con ventaja» y respetase la oposición interna ${ }^{45}$.

A pesar de la distancia, la prensa italiana mostró especial interés por el tema. El propio PCI se mostró sorprendido por la repercusión mediática del artículo. La dirección comunista se vio obligada a publicar una nota en la que indicaba que no había silenciado nada y que siempre había intentado dar respuesta documentada a los interrogantes que afectaban a la vida del partido. Pero el contexto de 1988 propició la ocasión perfecta para un juicio sobre la «ambigüedad del PCI». Una ambigüedad que se habría prolongado en el tiempo: en los años cincuenta, en el intento de suavizar la desestalinización y en los sesenta, exaltando la figura de Dubček, solidarizándose con el nuevo curso - la «ineguagliabile esperienza» - y, tras la invasión, «l'augurio di "pieno successo" alla nuova direzione cecoslovacca impersonata da Husák» ${ }^{46}$. Ya en los setenta, en "el intento de mantener el cordón umbilical» entre renovación democrática y el pasado ejemplificado en $1917^{47}$. $\mathrm{Y}$, finalmente, en la década de los ochenta, en la búsqueda de un camino entre socialdemocracia y Socialismo Real que no conllevase la ruptura con la URSS.

El PCI decidió unir fuerzas en torno a la memoria orgánica de Togliatti, si bien obviando cualquier tipo de especulación sobre la cuestión de salvar a Gramsci. El primero en entrar en la arena fue Giorgio Napolitano con un artículo titulado «Parole e silenzi di Togliatti» ${ }^{48}$. En él, el que posteriormente fue Presidente de la República recordaba el contexto en el que Togliatti tuvo que

\footnotetext{
${ }^{43}$ NAPOLITANO, Giorgio, Dal Pci al socialismo europeo. Un'autobiografia politica, Roma-Bari, Editori Laterza, 2005 , p. 229.

${ }^{44}$ GUERRA, Adriano, op. cit., p. 333.

${ }^{45}$ La carta de Gramsci enviada a Moscú a Togliatti, su respuesta y la réplica del autor in GRAMSCI, Antonio, Le opere. La prima antologia di tutti gli scritti, Roma, Editori Riuniti, 1997, pp. 164-178.

${ }^{46}$ SALVADORI, Massimo L., L'utopia caduta: storia del pensiero comunista da Lenin a Gorbaciov, Roma-Bari, Laterza, 1991, p. 694.

${ }^{47}$ ELORZA, Antonio, Eurocomunismo y tradición comunista in Vías democráticas al socialismo, Madrid, Ed. Ayuso, 1981, p. 98.

${ }^{48}$ L'Unità, 21 de febrero de 1988.
} 
tomar decisiones de gran relevancia, pues en caso contrario no se podrían "comprender fenómenos y hechos característicos de aquel período», añadiendo que "solo reflexionando sobre las contradicciones que hoy aparecen tan estridentes se puede vislumbrar la trágica complejidad de aquel tiempo». Napolitano explicaba así el giustificazionismo histórico de Togliatti. Subrayó que su acción había oscilado entre «momentos de valiente desarrollo y frenadas». Lo único que le reprochaba era no haber realizado nunca «una explícita y sustancial revisión de su laudatorio juicio de la URSS» ${ }^{49}$.

Más combativo resultó Pietro Ingrao que en su artículo «Fin dove arrivò Togliatti» evitó cualquier tipo de acusación, marcando abiertamente las distancias frente a quienes intentasen convertir al líder comunista en un «imputado» olvidando su papel histórico y su aportación al comunismo italiano $^{50}$. Ingrao defendió la «justeza de las elecciones políticas» de Togliatti. El pasaje más notable del artículo era aquel en que argumentó que cuando Togliatti «aceptó y aprobó las represiones sanguinarias e injustas», lo hizo porque "quería salvar una perspectiva histórica, una posibilidad de actuar» ${ }^{51}$. Aceptó, por tanto, en aras de defender un ideal superior, la Revolución de Octubre.

Asimismo en «L'Unità», Paolo Bufalini escribió que la conducta de Togliatti se vio impuesta por la necesidad de situarse en un bando en un contexto de confrontación mundial. De los tres políticos comunistas en dar su visión en aquellos días de finales de los ochenta fue el más suave. Tras una crítica inicial al mundo bipolar, reprochó a Togliatti no haber conseguido «encuadrar históricamente el estalinismo». E indicó que «en la denuncia de los errores y de los horrores se perdía la visión global de la Revolución de Octubre, de la construcción del socialismo en un sólo país, de la guerra y de la victoria sobre el nazismo». Por su parte, Nilde Iotti, presidenta de la Cámara e histórica pareja sentimental del líder italiano, intervino en la polémica recordando que hablar de Togliatti y de su labor significaba rememorar las décadas más trágicas de la Europa moderna. En su opinión, il Migliore siempre había actuado en interés del partido en un momento en que era, no sólo conveniente sino necesario, mantener un estrechísimo vínculo con la URSS.

Aunque se trató de una polémica marcadamente italiana, a medida que se agudizaba la crisis del bloque del Este se dieron dinámicas parecidas en otros partidos comunistas en términos de revisión crítica en un contexto, además, en que sectores de la intelectualidad comunista -Manuel Azcárate, por ejemplo- adoptaban de forma explícita una visión de Octubre como sucesos de «otro siglo».

En los ochenta, los retrocesos electorales conllevaron un encendido debate sobre la identidad de los partidos comunistas de Italia y de España. Terminada la etapa eurocomunista, se

\footnotetext{
${ }^{49}$ Ibidem.

${ }^{50} 27$ de febrero de 1988. Véase INGRAO, Pietro, Interventi sul campo, Napoli, Cuen, 1990, pp. 67-73.

${ }^{51}$ Ibidem.
} 
cuestionaban las decisiones tomadas por sus históricos líderes. Se señaló cómo el policentrismo de Togliatti, el «compromiso histórico» de Berlinguer o la táctica enunciada en el libro Eurocomunismo y Estado de Carrillo, no habían cosechado los resultados esperados. El eurocomunismo fue un intento de «ir más allá de la experiencia comunista y de la socialdemócrata $»^{52}$. Se creyó posible conseguir por la vía democrática las ansiadas reformas que llevarían al socialismo dentro del capitalismo. Sin embargo, su fracaso provocó que las expectativas fueran sustituidas por el desencanto y la decepción de la militancia. Aunque cada partido llegó a ese punto marcado por las peculiaridades de su situación, tanto para el PCI como para el PCE el final del eurocomunismo se saldó con críticas, transfuguismos y escisiones.

\section{Algunas conclusiones}

La polémica política, pero con invocaciones historiográficas, sobre la figura de Togliatti estalló en el momento en que los partidos comunistas de Italia y de España afrontaban una situación crítica, con una gravísima erosión electoral en vísperas del colapso del Socialismo Real. En el caso de Italia, el último secretario comunista, Achille Occhetto, acabó impulsando una estrategia y una revisión ideológica que terminó suponiendo, en cierto modo, el regreso a 1902 y a la socialdemocracia en vísperas de la fractura entre bolcheviques y mencheviques. Un año antes de la caída del Muro, en una célebre entrevista, Occhetto, entonces vice-secretario del PCI, invitó a «una radical recolocación histórica de la Revolución de Octubre y de todo el complejo movimiento» de ella derivado ${ }^{53}$. En su opinión, se trataba de "relativizar» su significado. E, incluso, dio a entender que el PCI se sentía más heredero de la tradición revolucionaria francesa de 1789 que de la soviética. Dos días después un cuadro comunista histórico, Armando Cossutta, definió aquellas palabras como reflexión «desconcertante que sabe a capitulación» ${ }^{54}$.

Desde hacía años el PCI o el PCE descartaban la ruptura violenta o la posibilidad de una revolución armada. Para alguna otra voz autorizada de los años ochenta la llave del cambio debía apoyarse en los padres fundadores. «Marx y Engels jamás identificaron la revolución social exclusivamente con su forma violenta [...]. Para toda una serie de países -entre ellos Inglaterra, Estados Unidos y Holanda-, Marx contempló la posibilidad de una transición pacífica al socialismo», se afirmó desde este posicionamiento revisionista ${ }^{55}$. 1917 seguía considerándose como momento capital en términos históricos, punto de ruptura con el capitalismo y mito

\footnotetext{
${ }^{52}$ CHIARANTE, Giuseppe, La fine del PCI. Dall'alternativa democratica di Berlinguer all'ultimo congresso (1979-1991), Roma, Carocci, 2009, p. 35.

${ }^{53}$ OCCHETTO, Achille, «Il passato è sepolto», in La Repubblica, 10 de marzo de 1988, p. 5.

${ }^{54}$ L'Unità, 12 de marzo de 1988, p. 2.

${ }^{55}$ SCHAFF, Adam, El comunismo en la encrucijada, Barcelona, Crítica, 1983, p. 38.
} 
fundacional. Pero a la hora de establecer la fundamentación histórica de la naturaleza revolucionaria, esta se retrotraía hasta el siglo XIX en forma de interpretación selectiva.

Se ponía un punto final así, en la estela última generada desde el eurocomunismo, a los usos simbólicos de la memoria, cerrándose un ciclo. En 1937, en pleno apogeo del fascismo y con un PCI clandestino, la huella de la Revolución de Octubre fue intensamente exportada según el canon estalinista, en un proceso de adaptación local que cabría tildar, respecto a la España en guerra, de españolización simbólica. En 1949, con un PCI trastocado en partido de masas y un PCE disgregado entre la represión, la clandestinidad y el exilio, tuvo lugar un reforzamiento de la sovietización simbólica en la cultura comunista global, al socaire de la Guerra Fría. 1956 supuso, en cambio, una suerte de transacción entre desacralización simbólica (desestalinización), modulación selectiva de sentido de 1917 y nacionalización tanto en el PCI como en el PCE. Por fin, a finales de los ochenta, y nuevamente en el caso paradigmático del PCI, 1917 se encapsuló como episodio que podía seguir manteniendo una fuerte carga sentimental, pero cada vez más encerrado en sus condicionantes históricos, y definitivamente desahuciado de una virtual aplicación, en clave sistémica, en términos de presente y futuro sobre esa misma realidad nacional. 


\section{LOS AUTORES}

Andrea DONOFRIO es Profesor de la UCM. Sus investigaciones se han centrado en la historia de los movimientos políticos y sociales, el pensamiento y las ideas políticas, especialmente de las formaciones de extrema izquierda y derecha. Es autor de numerosos artículos científicos y del libro Érase una vez el eurocomunismo. Las razones de un fracaso (Madrid, Tecnos, en imprenta). También es co-autor del libro Historia actual del mundo. De la posguerra a la cultura global (Madrid, Síntesis, 2016).

URL: < http://www.studistorici.com/progett/autori/\#Donofrio >

José Carlos RUEDA LAFFOND es Profesor Titular en la UCM. Sus investigaciones se han centrado en la historia urbana, la historia de la imagen o las relaciones entre historia y memoria. Es autor de numerosos artículos científicos y de una decena de libros, entre los que resaltan Imágenes y palabras. Medios de comunicación y públicos contemporáneos (Madrid, CIS-Siglo XXI, 2005), Historia de los medios de comunicación (Madrid, Alianza, 2014) o Historia actual del mundo. De la posguerra a la cultura global (Madrid, Síntesis, 2016).

URL: < http://www.studistorici.com/progett/autori/\#RuedaLaffond > 